CLINICAL STUDY

\title{
Histology and immunohistochemistry of the parathyroid glands in renal secondary hyperparathyroidism refractory to vitamin D or cinacalcet therapy
}

\author{
Carlo Vulpio ${ }^{1}$, Maurizio Bossola ${ }^{1}$, Enrico Di Stasio ${ }^{2}$, Luigi Tazza ${ }^{1}$, Patrizia Silvestri ${ }^{1}$ and Guido Fadda ${ }^{3}$ \\ ${ }^{1}$ Istituto di Clinica Chirurgica, ${ }^{2}$ Istituto di Biochimica and ${ }^{3}$ Istituto di Anatomia e Istologia Patologica, Università Cattolica del Sacro Cuore, Largo A. \\ Gemelli, 8, Rome 00168, Italy
}

(Correspondence should be addressed to C Vulpio; Email: c.vulpio@alice.it)

\begin{abstract}
Background: Cinacalcet is a new effective treatment of secondary hyperparathyroidism (SHPT) in hemodialysis patients (HP), but the alterations of parathyroid gland (PTG) hyperplasia determined by cinacalcet and vitamin D have not been extensively investigated in humans.

Methods: We performed histological analyses of 94 PTGs removed from 25 HP who underwent parathyroidectomy (PTx) because of SHPT refractory to therapy with vitamin D alone (group A=13 $\mathrm{HP}$ and 46 PTGs) or associated with cinacalcet (group $\mathrm{B}=12 \mathrm{HP}$ and 48 PTGs). The number, weight, the macroscopic cystic/hemorrhagic changes, and type of hyperplasia of PTG (nodular $=\mathrm{NH}$, diffuse $=\mathrm{DH}$ ) were assessed. In randomly selected HP of group A (4 HP and 14 PTGs) and group B (4 HP and 15 PTGs), the labeling index of cells positive to Ki-67 and TUNEL and the semiquantitative score of immunohistochemistry staining of vitamin D receptor, calcium-sensing receptor, and vascular endothelial growth factor- $\alpha$ (VEGF- $\alpha$ ) were measured in the entire PTGs and in the areas with DH or NH.

Results: The number and weight of single and total PTG of each HP were similar in the two groups as well as the number of PTG with macroscopic cystic/hemorrhagic areas. TUNEL, Ki-67, and VEGF- $\alpha$ scores were higher in $\mathrm{NH}$ than in $\mathrm{DH}$ areas.

Conclusion: This observational study of a highly selected population of HP, submitted to PTx because SHPT refractory to therapy, shows that the macroscopic, microscopic, and immunochemistry characteristics of PTG in HP who received or did not receive cinacalcet before PTx did not differ significantly.
\end{abstract}

European Journal of Endocrinology 168 811-819

\section{Introduction}

Secondary hyperparathyroidism (SHPT) amongst chronic hemodialysis patients (HP) is characterized by parathyroid gland (PTG) hyperplasia and excessive synthesis and secretion of intact parathyroid hormone (iPTH), resulting in unbalanced bone reabsorption, soft tissue and vascular calcification, and significantly increased risk for cardiovascular morbidity and mortality $(1,2,3,4)$. The hypersecretion of iPTH is associated with an increase in the PTG size, initially characterized by diffuse polyclonal hyperplasia (DH) and subsequently by nodular hyperplasia $(\mathrm{NH})(5,6,7)$. SHPT sustained by $\mathrm{NH}$ is an irreversible condition usually refractory to conventional medical treatment or renal transplantation and it is classically defined as tertiary hyperparathyroidism (THPT). The failure of medical therapy is primarily due to progressive downregulation $(8,9,10)$ of both calcium-sensing receptors (CaSR) and vitamin D receptors (VDR) $(4,11,12,13)$.
Actually, it is widely acknowledged that the PTG volume (maximum diameter $>10 \mathrm{~mm}$ or volume $>500 \mathrm{~mm}^{3}$ ) negatively influences the response to calcitriol or vitamin D analog treatment $(14,15)$. In these cases, parathyroidectomy (PTx) may be indicated (16). Conversely, it remains to be determined whether cinacalcet may determine regression of PTG hyperplasia (2). Cinacalcet increases the sensitivity of CaSR to activation by extracellular $\mathrm{Ca}$ and suppresses the release of iPTH. The CaSR play a key role in the excessive cell proliferation in PTG hyperplasia $(17,18,19,20,21$, $22,23)$. In humans, the regression of PTG hyperplasia has been reported rarely, in cases of spontaneous infarction of the glands $(24,25)$ and in cases of $\mathrm{DH}$ after kidney transplantation $(26,27)$.

Recently, ultrasonography (US) of the PTG has been performed in HP to examine the changes of PTG volumes after cinacalcet treatment. Some authors $(28,29,30)$ reported a significant reduction in the PTG volume from baseline to the end of the follow-up. 
Moreover, morphological changes in PTG during cinacalcet treatment, such as cystic degeneration and hypovascularization, were observed by US. Conversely, other authors $(31,32)$ failed to detect significant morphological changes after cinacalcet therapy.

To this date, it has not been fully elucidated whether patients with established $\mathrm{NH}$ can be controlled by cinacalcet therapy in the long term. Moreover, the hypothetical regression of the volume of PTG (reduction of cell proliferation and/or increase in cell apoptosis) in relation to the degree of glandular hyperplasia and to the type of treatment is still an argument for debate $(33,34)$.

The main purpose of this study was to assess whether there are differences in the histology (i.e. weight and number of PTG, type of hyperplasia ( $\mathrm{NH}$ vs $\mathrm{DH}$ ), cystic/necrotic degeneration, and expression of the different cell types) and immunohistochemistry (TUNEL, Ki-67, vascular endothelial growth factor- $\alpha$ (VEGF- $\alpha$ ), VDR, and CaSR) of PTG of HP affected by SHPT refractory to vitamin D or vitamin D associated with cinacalcet long-term therapy.

\section{Materials and methods}

\section{Patients and study design}

In this retrospective study, 25 consecutive HP with severe SHPT who underwent total (17 HP) or subtotal (8 HP) PTx at the Department of Surgery of the Catholic University of Rome from January 2004 to February 2011 were included. All patients were referred to our center from other dialysis units of our region. Indication for PTx was based on NKF-DOQI guidelines (1) (i.e. i) abnormalities in mineral metabolism (hypercalcemia or phosphatemia); ii) elevated iPTH levels (>800 pg/ml); iii) nonresponsiveness to medical treatment; and iv) enlarged PTG (>10 mm of diameter) detected by image diagnosis).

On the basis of preoperative treatment, the HP were divided into two groups: group A (13 HP and 46 PTGs) including HP who underwent vitamin D therapy (calcium supplements, phosphate binders, and active vitamin D analogs) without cinacalcet and group B (12 HP and 48 PTGs) including HP treated with vitamin D associated with cinacalcet.

\section{Macroscopic characteristics of PTG}

The number, weight, and maximum longitudinal diameter (MLD) of all PTGs removed in each patient were determined immediately after PTx in the operating room. During macroscopic examination of the longitudinal sections of PTG, the presence of foci of cystic/hemorrhagic necrosis was also determined (Fig. 1a) and then confirmed by histology (Fig. 1b).

\section{Histology of PTG tissues}

All histological specimens were fixed in $10 \%$ buffered formaldehyde, embedded in paraffin, and the $5 \mu \mathrm{m}$ thick sections were stained with hematoxylin-eosin for the histological examination. The type of hyperplasia was classified as either DH (type 1) or NH (types 2-4) according to Tominaga et al. (4). The DH was defined as an increased number of parenchymal cells with normal lobular structures, and the $\mathrm{NH}$ was defined as at least one well-circumscribed, encapsulated, and virtually fat cell-free accumulation of parenchymal cells. Furthermore, the type of $\mathrm{NH}$ was classified as follows: early or micronodular (multiple microscopic nodules: the singlecell type tends to form nodules lacking fibrous bands (type 2)), macronodular (multiple macroscopic encapsulated nodules (type 3)), and single nodule or adenoma like (PTG hyperplasia characterized by a single markedly enlarged nodule of uniform parenchymal cell proliferation resembling adenoma and suppressing the adjacent parathyroid tissue (type 4)). The number of chief cell (CC), oxyphil cells (OC), and water cells (WC) was expressed as mean percentage of total cells detected

(a)
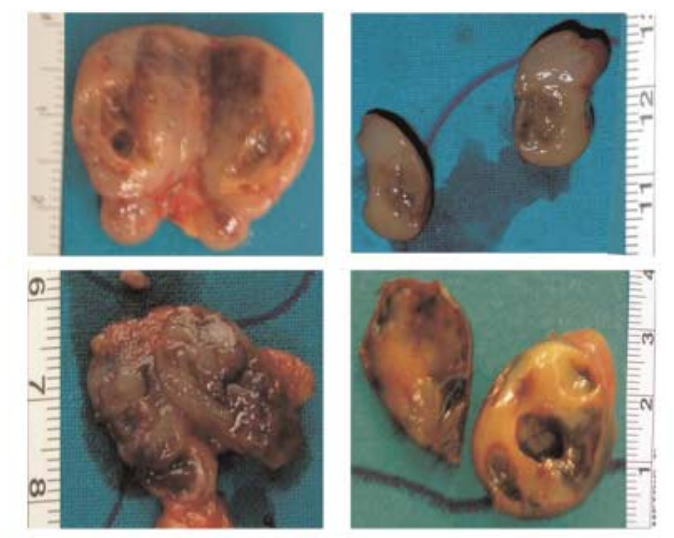

(b)

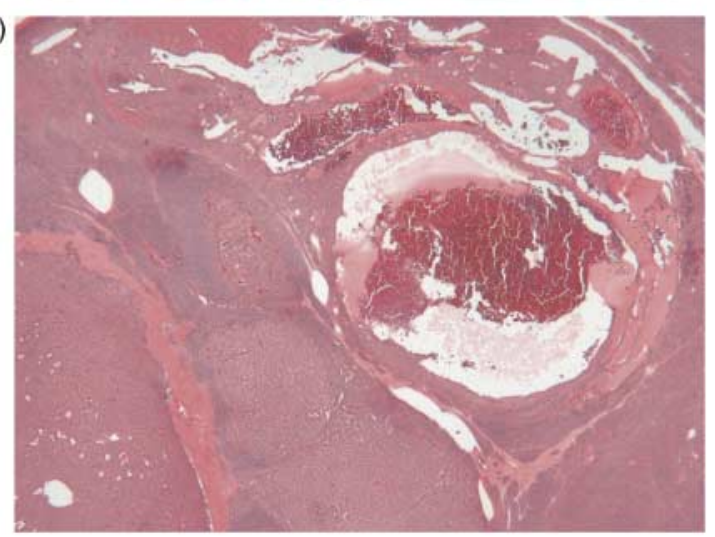

Figure 1 (a) Macroscopic examination of longitudinal section of PTG with cystic/hemorrhagic areas; and (b) histopathological image of hemorrhagic necrosis of PTG (hematoxylin and eosin stain). Full colour version of this figure available via http://dx.doi.org/ 10.1530/EJE-12-0947. 

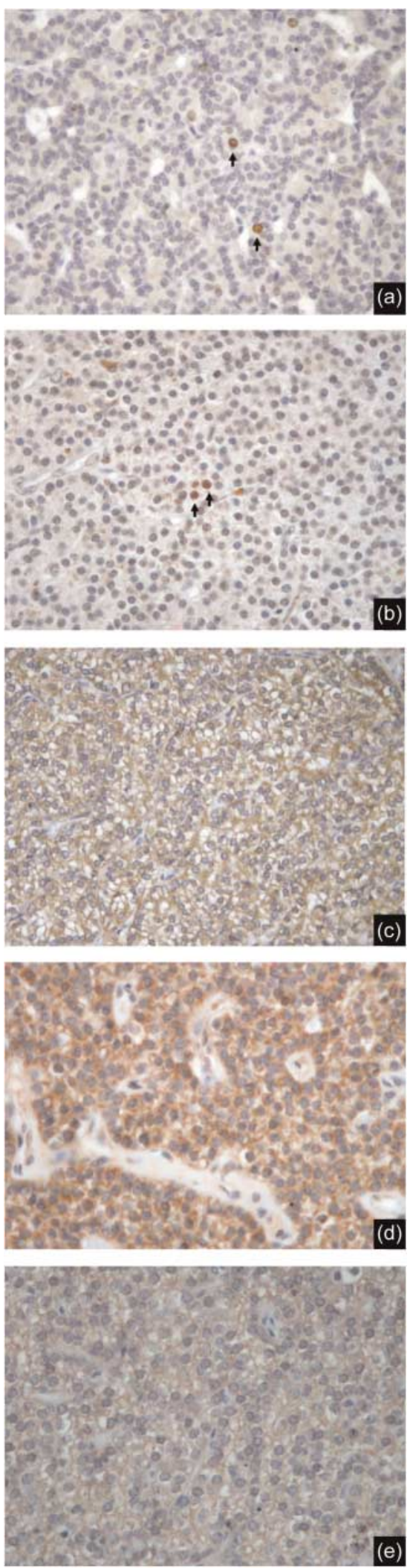

at a magnification of $\times 200$ in ten randomly selected fields of glandular section (five in areas with $\mathrm{DH}$ and five in areas with $\mathrm{NH}$ ), which was evaluated in each PTG.

\section{Immunohistochemistry}

Fourteen PTGs of four randomly selected HP out of $13 \mathrm{HP}$ of group A and 15 PTGs of 4 out of $12 \mathrm{HP}$ of group B were studied by immunohistochemistry. According to the manufacturer's instructions and dilutions, immunostains for Ki-67 (nuclear protein expressed in proliferating cells) (Antibody (SP6) Novus Biologicals, Littleton, CO, USA), TUNEL (Mebstain Apoptosis kit II, Immunotech and Diagnostic System Laboratories, Marseille, France), VEGF- $\alpha$ (rabbit polyclonal IgG VEGF- $\alpha$ (A-20) Antibody:sc-152 Santa Cruz Biotechnology), VDR (Vitamin D Receptor Antibody (2F4) Novus Biologicals), and CaSR antibody (calciumsensing receptor ab 27493, Abcam, Inc., Cambridge, MA, USA) were performed on the microtomic sections using the labeled streptavidin-biotin-peroxidase complex system $(\mathrm{ABC})$. The tissues were incubated with commercial monoclonal antibodies after a prior microwave antigen retrieval (3-min passages in citrate buffer; $\mathrm{pH}$ 6.0) and the final results were revealed with 3,3'-diaminobenzidine.

\section{Quantitative evaluation of positive cells}

According to Wada et al. (13), the cells were considered Ki-67 positive when a dark brown staining of the nucleus was observed; on the other hand, cells were considered TUNEL positive when black nuclei, corresponding to a marked condensation of nuclear chromatin, were observed (Fig. 2a and b). Areas of obvious necrosis were excluded from counting. The mean number of Ki-67- and TUNEL-positive cells was counted using a $\times 40$ objective lens under a light microscope in ten selected high-power fields showing 200-500 cells per field. The mean labeling index (LI\%) was determined as the number of positive cells per 100 counted cells. The ten fields were randomly selected as follows: i) for diffuse and single nodule (adenoma like) glands, five fields around the periphery and five in the center fields of each gland were selected, and ii) for early and multi-nodular glands, five fields around the areas of $\mathrm{DH}$ and five in the areas containing $\mathrm{NH}$ were selected.

The VEGF- $\alpha$, VDR, and CaSR staining (Fig. 2c, d, and e) was semiquantitatively assessed according to a scale previously defined by Martins et al. (35): 0 (0 cells

Figure 2 Representative findings of immunohistochemical staining of parathyroid tissue: (a) Ki-67 (the arrows indicate the Ki67-positive cells); (b) TUNEL assay (the arrows indicate positive cells); (c) VEGF- $\alpha$, vascular endothelial growth factor- $\alpha$; and (d) VDR, vitamin D receptor; (e) CaSR, calcium-sensing receptor. Full colour version of this figure available via http://dx.doi.org/ 10.1530/EJE-12-0947. 
stained), 1 ( $<25 \%$ cells with mild staining), 2 (25-74\% cells with moderate staining), and 3 (>75\% cells with intense staining). Repeat recounts for Ki-67 and TUNEL, VEGF- $\alpha$, VDR, and CaSR conducted by the same examiner in all PTGs showed variability of $\mathrm{LI} \%$ and scores $\leq \pm 5 \%$ from the original counts.

\section{Statistical analysis}

Data were analyzed by MedCalc Software (Belgium Version 12 - for Microsoft Windows XP). Continuous variables were expressed as mean \pm s.D. and categorical and interval variables as frequencies or median and interquartile range. The appropriate test was used when comparing the groups' means ( $t$-test, ANOVA-StudentNewman-Keuls post hoc comparison) or median (independent Mann-Whitney $U$ test and paired Wilcoxon test) and frequencies (Fisher's exact test or $\chi^{2}$ test, Kruskal-Wallis). The correlations between two variables were calculated by parametric test (Pearson's correlation test) or nonparametric test (Spearman's coefficient of correlation). Multiple linear regressions with backward stepwise procedure were also performed to study the relationship between Ki- 67 , tunnel, VEGF- $\alpha$, VDR, and CaSR and clinical and laboratory parameters. Covariates introduced in the models were variables significantly correlated at the univariate analysis. $P<0.05$ was considered statistically significant.

\section{Results}

The demographic, clinical, and laboratory characteristics of HP of groups A and B are shown in Table 1 . Preoperative serum Ca levels were significantly lower in group B than in group A $(10.1 \pm 0.6$ and $9.2 \pm 0.9 \mathrm{mg} / \mathrm{dl}$ respectively; $P<0.016$ ) and the length of treatment was higher in group B than in group A $(18.1 \pm 5.4$ and $13.2 \pm 4.1$ months respectively; $P<0.0001)$.
The macroscopic characteristics of the 94 PTGs removed in $25 \mathrm{HP}$ (46 PTGs in group A and 48 PTGs in group B) are shown in Table 2. The total number, the MLD, and the weight of single and total PTGs of each HP were similar in the two groups as well as the number of PTGs with macroscopic cystic/hemorrhagic areas. The MLD and the weight of the PTG with hemorrhagic areas were higher than the PTGs without cystic/hemorrhagic areas $(17.1 \pm 4.4$ and $11.8 \pm 5.3 \mathrm{~mm}$ respectively, $P<0.002$; and $2.1 \pm 0.9$ and $1.0 \pm 0.7 \mathrm{~g}$ respectively, $P<0.0001)$. The logistic regression coefficients of a model including weight, type of hyperplasia of PTGs, and type and duration of medical treatment showed that the weight of PTG (coefficient 1.34, s.E.M. 0.49, $P<0.006)$ only predicted the presence of cystic/ hemorrhagic areas.

As shown in Table 3, 17 PTGs (18.1\%) showed DH and $77(81.9 \%)$ showed NH. The percentage of PTGs with $\mathrm{DH}$ and $\mathrm{NH}$ was similar in groups $\mathrm{A}$ and $\mathrm{B}$. The MLD and the weight were significantly lower in PTGs with DH than in PTGs with $\mathrm{NH}$ (7.2 \pm 3.9 vs $13.1 \pm$ $5.1 \mathrm{~mm}, P<0.001$, and $0.48 \pm 0.49$ vs $1.27 \pm 1.1 \mathrm{~g}$, $P<0.005$ respectively). In addition, the percentage of the constituent cells of PTGs as well as the OC:CC ratio was as similar in group $\mathrm{A}$ and in group $\mathrm{B}$.

The immunostaining scores of VEGF- $\alpha$, VDR, and CaSR and the LI\% of TUNEL and Ki-67 corresponding to the DH and NH areas of PTG are shown in Tables 4 and 5. Overall, either in group A or in group B, the TUNEL and Ki-67 LI\% and VEGF scores were significantly higher in $\mathrm{NH}$ than in $\mathrm{DH}$ areas. Conversely, VDR and CaSR scores were similar in $\mathrm{DH}$ and $\mathrm{NH}$ areas. In $\mathrm{DH}$ and $\mathrm{NH}$ areas of PTG of group B, with respect to group A, the VEGF score was lower but not statistically significant ( $\chi^{2}$ for trend respectively 0.007 and 0.032).

Linear multivariate regressions showed that: i) the TUNEL LI\% index was directly correlated with Ki-67 $(P=0.001)$, VEGF- $\alpha(P=0.010)$, Ca serum concentrations $(P=0.002)$, and iPTH serum levels $(P=0.002)$ and indirectly correlated with alkaline phosphatase

Table 1 Clinical, biochemical, and therapeutic characteristics of patients with SHPT refractory to conventional therapy without (group A) and with cinacalcet (group B). Data are presented as mean \pm S.D.

\begin{tabular}{|c|c|c|c|c|}
\hline & All patients & Group A & Group B & $P$ value \\
\hline$n$ & 25 & 13 & 12 & \\
\hline Age (years) & $51.1 \pm 17.2$ & $45.5 \pm 18.3$ & $57.2 \pm 14.1$ & 0.088 \\
\hline $\mathrm{F} / \mathrm{M}$ & $7 / 18$ & $4 / 9$ & $3 / 9$ & \\
\hline Dialysis duration (years) & $4.1 \pm 2.2$ & $4.2 \pm 2.5$ & $3.9 \pm 1.8$ & 0.724 \\
\hline $\mathrm{Ca}(\mathrm{mg} / \mathrm{dl})$ & $9.7 \pm 0.8$ & $10.1 \pm 0.6$ & $9.2 \pm 0.9$ & 0.016 \\
\hline $\mathrm{Pi}(\mathrm{mg} / \mathrm{dl})$ & $6.6 \pm 1.7$ & $6.5 \pm 1.6$ & $6.7 \pm 1.9$ & 0.721 \\
\hline ALP (IU/I) & $478.7 \pm 520.4$ & $457.9 \pm 468.4$ & $501.5 \pm 594.4$ & 0.846 \\
\hline iPTH (pg/ml) & $1156 \pm 536$ & $1004 \pm 602$ & $1274 \pm 448$ & 0.294 \\
\hline Total therapy (months) & $15.9 \pm 5.4$ & $13.2 \pm 4.1$ & $18.1 \pm 5.4$ & 0.001 \\
\hline Dose calcitriol ( $\mu \mathrm{g} /$ week $)$ & & $2.9 \pm 0.5$ & $3.3 \pm 0.9$ & 0.243 \\
\hline Dose cinacalcet (mg/week) & & & $73.8 \pm 12.8$ & \\
\hline
\end{tabular}

$\mathrm{Pi}$, inorganic phosphorus; ALP, alkaline phosphatase activity; iPTH, intact parathyroid hormone serum concentrations. 
Table 2 Macroscopic characteristics of parathyroid gland (PTG).

\begin{tabular}{|c|c|c|c|c|}
\hline & All patients & Group A & Group B & $P$ value \\
\hline Patients and (PTG) & $25(94)$ & $13(46)$ & $12(48)$ & \\
\hline MLD $(\mathrm{mm})$ of PTG mean \pm s.D. & $12.1 \pm 5.4$ & $11.2 \pm 5.5$ & $12.9 \pm 5.2$ & 0.142 \\
\hline Weight $(\mathrm{g})$ of PTG mean \pm s.D. & $1.1 \pm 1.0$ & $1.0 \pm 1.4$ & $1.2 \pm 0.8$ & 0.504 \\
\hline No. of PTG for patient median (IQR) & $4(3-4)$ & $4(3-4)$ & $4(3.5-4)$ & 0.453 \\
\hline Weight of largest PTG & $1.9 \pm 0.8$ & $1.8 \pm 0.8$ & $2.1 \pm 0.7$ & 0.517 \\
\hline Total weight PTG mean \pm S.D. & $4.4 \pm 2.0$ & $4.0 \pm 2.1$ & $4.4 \pm 1.8$ & 0.330 \\
\hline PTG with hemorrhagic areas $n(\%)$ & $16(17)$ & $6(13)$ & $9(19)$ & 0.576 \\
\hline MLD with hemorrhagic areas & $17.1 \pm 4.4^{*}$ & $18.3 \pm 5.1$ & $16.5 \pm 4.2$ & $0.002^{*}$ \\
\hline MLD without hemorrhagic areas & $11.8 \pm 5.3^{*}$ & $11.5 \pm 5.1$ & $12.1 \pm 5.6$ & \\
\hline Weight with hemorrhagic areas & $2.1 \pm 0.9^{\dagger}$ & $2.9 \pm 0.4$ & $1.9 \pm 0.9$ & $0.001^{\dagger}$ \\
\hline Weight without hemorrhagic areas & $1.0 \pm 0.7^{\dagger}$ & $0.9 \pm 0.6$ & $1.0 \pm 0.7$ & \\
\hline
\end{tabular}

MLD, maximum longitudinal diameter; IQR, interquartile range. *Indicates significant difference $(P=0.002)$ in the MLD with and without hemorrhagic mass; ${ }^{\dagger}$ indicates significant difference $(P=0.001)$ in weight with and without hemorrhagic mass.

activity $(\mathrm{ALP})\left(P=0.033 ; R^{2}=0.663\right)$; ii $)$ the Ki-67 LI\% was directly correlated with TUNEL $(P<0.05)$, serum inorganic phosphorus $(\mathrm{Pi})$ concentrations $(P=0.039)$, and ALP $\left(P=0.007 ; R^{2}=0.440\right)$; iii) the VEGF- $\alpha$ score was directly correlated with $\mathrm{Pi}\left(P=0.003 ; R^{2}=0.315\right)$; and iv) the VDR score was directly correlated with $\mathrm{Pi}$ $(P<0.001)$ and indirectly correlated with Ca $(P=0.001)$ and iPTH $\left(P=0.008 ; R^{2}=0.663\right)$. The small size of the sample did not allow to compare the immunohistochemical expression of the different markers in all types of hyperplasia.

\section{Discussion}

This study shows that the histology and immunohistochemistry of PTG of HP who received or did not receive cinacalcet before PTx did not differ significantly. In particular, the proliferating (Ki-67) and apoptotic cells (TUNEL) and the expression of VEFG- $\alpha$, VDR, and
CaSR were overall similar in the PTGs of the HP of two groups. To the best of our knowledge, this is the first study that extensively evaluates the histology of PTG as well as the expression of makers of cell proliferation, apoptosis, and angiogenesis of PTG of HP who received or did not receive cinacalcet before PTx.

Indeed, data on the effect of cinacalcet on the pathology of human PTG in HP with SHPT are very few $(33,34,36)$. Lomonte et al. did not find significant differences in the number, weight, and percentage of $\mathrm{NH}$ in the PTG of patients who received calcitriol and cinacalcet with respect to those who received calcitriol only. With regard to the expression of the different cell types, the author reported that, despite the short-term therapy (for $3.3 \pm 1.8$ months), the OC:CC ratio was significantly higher in patients treated with cinacalcet. Sumida et al. (34) also reported that the percentage of OC area to the total area was significantly higher in the cinacalcet group (duration of treatment 16.1 \pm 6.8 months) compared with the conventional group. In this

Table 3 Microscopic characteristics of PTG of patients with SHPT refractory to conventional therapy without (group A) and with cinacalcet (group B).

\begin{tabular}{|c|c|c|c|c|}
\hline & All patients & Group A & Group B & $P$ value \\
\hline Patients and PTG $(n)$ & $25(94)$ & $13(46)$ & $12(48)$ & \\
\hline Diffuse hyperplasia (DH) PTG (\%) & $17(18.1)$ & $11(23.9)$ & $6(12.5)$ & 0.242 \\
\hline Nodular hyperplasia (NH) PTG (\%) & 77 (81.9) & $35(76.1)$ & $42(87.5)$ & \\
\hline Early (micronodular) & $50(53.2)$ & $24(52.2)$ & $26(54.1)$ & 0.286 \\
\hline Macronodular & $11(11.7)$ & $3(6.5)$ & $8(16.7)$ & \\
\hline Single nodule (adenoma-like) & $16(17)$ & $8(17.4)$ & $8(16.7)$ & \\
\hline MLD (mm) PTG with DH & $7.2+3.9^{*}$ & $8.1+4.6$ & $5.7+1.2$ & $0.001^{*}$ \\
\hline MLD (mm) PTG with NH & $13.1 \pm 5.1^{*}$ & $12.2 \pm 5.4$ & $13.9 \pm 4.7$ & \\
\hline Weight $(\mathrm{g})$ PTG with DH & $0.48 \pm 0.49^{\dagger}$ & $0.54 \pm 0.53$ & $0.31 \pm 0.07$ & $0.005^{\dagger}$ \\
\hline Weight (g) PTG with NH & $1.27 \pm 1.1^{\dagger}$ & $1.29 \pm 1.53$ & $1.26 \pm 0.78$ & \\
\hline \multicolumn{5}{|l|}{ Cellularity (\% of total cells) } \\
\hline Chief cells $=\mathrm{CC}$ median (IQR) & $70(40-90)$ & $65(40-90)$ & $70(60-88)$ & 0.102 \\
\hline Oxyphil cells $=\mathrm{OC}$ & $20(10-32)$ & $20(10-40)$ & $20(10-20)$ & 0.208 \\
\hline Water clear cells $=W C$ & $10(0-11.5)$ & $1(0-11.5)$ & $12(0-11.5)$ & 0.724 \\
\hline Oxyphil cells:chief cells ratio & $0.25(0.11-0.67)$ & $0.25(0.12-0.67)$ & $0.43(0.11-1)$ & 0.187 \\
\hline
\end{tabular}

${ }^{*}$ Indicates significant difference $(P=0.001)$ between the MLD with $\mathrm{DH}$ and the MLD with $\mathrm{NH} ;{ }^{\dagger}$ indicates significant difference $(P=0.005)$ in weight with $\mathrm{DH}$ and the weight with $\mathrm{NH}$. 
Table 4 Labeling index of immunostaining of PTG of patients with SHPT refractory to vitamin D therapy without (group A) and with cinacalcet (group B).

\begin{tabular}{cclll}
\hline & All patients & Group A & \multicolumn{1}{c}{ Group B } & $\boldsymbol{P}$ value \\
\hline Ki-67 (mean \pm s.D.) & & & \\
DH & $1.0 \pm 0.9$ & $1.2 \pm 0.8$ & $0.8 \pm 0.9$ & 0.249 \\
NH & $2.2 \pm 1.5$ & $2.6 \pm 1.4$ & $1.8 \pm 1.4$ & 0.128 \\
$P$ value & $\mathbf{0 . 0 0 1}$ & $\mathbf{0 . 0 0 2}$ & $\mathbf{0 . 0 0 7}$ & \\
TUNEL (mean \pm s.D.) & & & \\
DH & $0.8 \pm 0.9$ & $1.0 \pm 1.4$ & $0.85 \pm 0.69$ & 0.731 \\
NH & $1.6 \pm 1.5$ & $1.5 \pm 1.8$ & $1.7 \pm 1.3$ & 0.745 \\
$P$ value & $\mathbf{0 . 0 0 9}$ & 0.183 & $\mathbf{0 . 0 1 5}$ & \\
\hline
\end{tabular}

${ }^{*} P$ values comparing groups $\mathrm{A}$ and $\mathrm{B}$. Ki-67, nuclear protein expressed in proliferating cells; $\mathrm{DH}$, areas of PTG with diffuse hyperplasia; $\mathrm{NH}$, areas of PTG with nodular hyperplasia.

study, we did not observe an increase in OC:CC ratio in the cinacalcet group compared with the vitamin D group. However, the increase in the $\mathrm{OC}$ :CC ratio observed after short- or long-term cinacalcet therapy did not translate into pharmacological control of SHPT. Certainly, the OC are not simply deactivated CC $(36,37,38,39,40,41)$. However, additional studies are required to define the effects of vitamin D and cinacalcet on the expression and role of the OC in the pathophysiology of PTG.

With regard to macroscopic characteristics of PTG, Sumida et al. (34) reported that, in the PTG of patients who received cinacalcet with respect to those treated with vitamin D, the weight of the maximal PTG and the weight ratio of maximal-to-minimal PTGs were significantly higher; there were no significant differences in either cystic or hemorrhagic score. In this study, although the length of treatment was greater in the cinacalcet group $(18.1 \pm 5.4$ months $)$ than in the conventional group, the number, the MLD, and the weight of PTGs were similar in both groups of patients. This observation is against the hypothesis that cinacalcet may decrease the size and volume of PTG in refractory SHPT sustained by advanced $\mathrm{NH}$ or adenoma-like hyperplasia. Nevertheless, this study does not allow to determine whether a regression of PTG with DH is possible after cinacalcet therapy. Actually, this hypothesis has been first based on the data obtained in experimental studies $(18,19,20,21$, $22,23)$ and then by the US evaluation of PTG $(28,29$, $30,31,32)$.

With regard to experimental studies, Mizobuchi et al. (19) demonstrated that high concentrations of calcimimetics determine apoptosis in parathyroid cells from 5/6 subtotal nephrectomized uremic rats in vitro. Conversely, others $(18,20)$ have failed to detect apoptosis in parathyroid cells in vivo. Finally, Chin et al. (20) demonstrated the possibility of regression of PTG size, but the reduction in PTG volume was attributed to a decrease in cell volume but not in cell number. Noteworthy, it is well known that experimental models of SHPT do not completely resemble the characteristics of human SHPT due to the lack of NH.

With regard to US, some authors reported that the PTG volume reduced significantly $(28,29,30)$, areas of cystic degeneration appeared, and glandular vascularization decreased (29) after cinacalcet therapy with consequent reduced functioning PTG mass. Indeed, in agreement with Sumida et al., we found that the number of PTG with macroscopic hemorrhagic or cystic areas was similar in the two groups of HP and that only the weight of PTG predicted the presence of hemorrhagic areas. In effect, very rarely smaller PTG $(\mathrm{MLD}<1 \mathrm{~cm}$ and weight $<1 \mathrm{~g}$ ) showed cystic/hemorrhagic areas. Noteworthy, we evaluated only the macroscopic hemorrhagic degeneration of PTG because we believe that only these alterations may be detected by US.

On the basis of the data of some authors showing a reduced vascularization in PTG of patients receiving cinacalcet, and on the basis of evidence of increased angiogenesis in pathological PTG compared with normal glands $(42,43,44,45)$, we also measured the expression of VEGF- $\alpha$ at the PTG level. VEGF- $\alpha$ plays a

Table 5 Scores for immunostaining of PTG of patients with SHPT refractory to vitamin D therapy without (group A) and with cinacalcet (group B).

\begin{tabular}{|c|c|c|c|c|c|c|c|c|c|c|c|c|c|}
\hline & \multicolumn{4}{|c|}{ All patients } & \multicolumn{4}{|c|}{ Group A } & \multicolumn{4}{|c|}{ Group B } & \multirow[b]{2}{*}{$P$ value $^{\star}$} \\
\hline & 0 & 1 & 2 & 3 & 0 & 1 & 2 & 3 & 0 & 1 & 2 & 3 & \\
\hline VEGF (scores) & & & & & & & & & & & & & $0.008^{\dagger}$ \\
\hline $\mathrm{DH}$ & 5 & 10 & 7 & 1 & 0 & 4 & 5 & 1 & 5 & 6 & 2 & 0 & 0.059 \\
\hline $\mathrm{NH}$ & 0 & 7 & 7 & 9 & 0 & 1 & 3 & 6 & 0 & 6 & 4 & 3 & 0.077 \\
\hline VDR (scores) & & & & & & & & & & & & & $0.358^{\dagger}$ \\
\hline $\mathrm{DH}$ & 7 & 14 & 2 & 0 & 4 & 4 & 2 & 0 & 3 & 10 & 0 & 0 & 0.111 \\
\hline $\mathrm{NH}$ & 8 & 15 & 0 & 0 & 5 & 5 & 0 & 0 & 3 & 10 & 0 & 0 & 0.613 \\
\hline CaSR (scores) & & & & & & & & & & & & & $0.389^{\dagger}$ \\
\hline $\mathrm{DH}$ & 1 & 10 & 6 & 6 & 0 & 4 & 4 & 2 & 1 & 6 & 2 & 4 & 0.497 \\
\hline $\mathrm{NH}$ & 4 & 7 & 8 & 4 & 2 & 3 & 3 & 2 & 2 & 4 & 5 & 2 & 0.968 \\
\hline
\end{tabular}

${ }^{*} P$ values comparing groups $\mathrm{A}$ and $\mathrm{B} ;{ }^{\dagger} P$ values comparing all patients with $\mathrm{DH}$ and $\mathrm{NH}$. VDR, vitamin $\mathrm{D}$ receptor; CaSR, calcium-sensing receptor; VEGF- $\alpha$, vascular endothelial growth factor- $\alpha$; DH, areas of PTG with diffuse hyperplasia; $\mathrm{NH}$, areas of PTG with nodular hyperplasia. 
key role in both physiological and pathological angiogenesis through the proliferation/migration of endothelial cells and increasing endothelial permeability. Moreover, VEGF- $\alpha$ is also an anti-apoptotic factor promoting the survival of endothelial cells in neo-formed vessels (42). Indeed, we found a lower expression of VEFG- $\alpha$ in both areas of PTG with DH and NH of group B than in those of HP of group A, although the difference was not statistically significant due to the small sample size. Although this finding is very interesting, our retrospective and observational study does not allow to establish a causative role of cinacalcet therapy in the reduced expression of VEFG- $\alpha$. Recent studies have shown that several angiogenic growth factors are produced and secreted by normal endocrine cells and are increased in pathological states of glands, including inflammation, hyperplasia, and neoplasia. However, in hyperplastic PTG due to SHPT, the increase in angiogenesis and apoptosis may occur simultaneously $(44,46)$. Although it has been hypothesized that a reduction of the size and volume of the PTG may result from a decreased cell proliferation and/or an increased apoptosis (2), this study shows that the LI of proliferating (Ki-67) and apoptotic cells (TUNEL) in PTG did not differ significantly between SHPT patients who received or did not receive cinacalcet before PTx.

This study has some limitations. First, the study is observational and reports associations. Secondly, the number of HP included in the study was relatively small and all patients were affected by THPT. The patients submitted to PTx represent a highly selected population. Indeed, the PTG had a relatively large size and most had NH $(87.5 \%)$. Thirdly, there was not a control group of patients without history of treatment with either vitamin D or cinacalcet. However, it is very difficult to have such patients to be included in cross-sectional studies because all HP with SHPT who undergo PTX usually have a history of treatment with vitamin D and/or cinacalcet. Fourthly, there was an unbalance in the duration of treatments between vitamin $\mathrm{D}$ and cinacalcet and this might have potentially affected the results. However, the longer duration of treatment was with cinacalcet.

In conclusion, the present retrospective and observational study shows that the macroscopic, microscopic, and immunochemistry characteristics of PTG of patients with advanced degree of parathyroid hyperplasia who received or did not receive cinacalcet long term before PTx did not differ significantly. However, the study does not allow to adequately clarify the hypothetical effects of cinacalcet on smaller PTG, which are usually detectable in SHPT responders to medical treatment (47).

\section{Declaration of interest}

The authors declare that there is no conflict of interest that could be perceived as prejudicing the impartiality of the research reported.

\section{Funding}

This research did not receive any specific grant from any funding agency in the public, commercial or not-for-profit sector.

\section{Acknowledgements}

The authors thank E Stigliano and P Lanza for histological preparations.

\section{References}

1 National Kidney Foundation. K/DOQI 2003 clinical practice guidelines for bone metabolism and disease in chronic kidney disease. American Journal of Kidney Diseases 200342 S1-S202. (doi:10.1053/S0272-6386(03)00905-3)

2 Drueke T, Martin D \& Rodriguez M. Can calcimimetics inhibit parathyroid hyperplasia? Evidence from preclinical studies Nephrology, Dialysis, Transplantation 200722 1828-1839. (doi:10.1093/ndt/gfm177)

3 Carrillo-López N, Fernández-Martín JL \& Cannata-Andía JB. The role of calcium, calcitriol and its receptors in parathyroid regulation. Nefrologia 200929 103-108. (doi:10.3265/Nefrologia. 2009.29.2.5154.en.full)

4 Tominaga Y, Tanaka Y, Sato K, Nagasaka T \& Takagi H. Histopathology, pathophysiology, and indications for surgical treatment of renal hyperparathyroidism. Seminars in Surgical Oncology 199713 78-86. (doi:10.1002/(SICI)1098-2388 (199703/04)13:2<78::AID-SSU3> 3.0.CO;2-Z)

5 Lewin E, Huan J \& Olgaard K. Parathyroid growth and suppression in renal failure. Seminars in Dialysis 200619 238-245. (doi:10.1111/j.1525-139X.2006.00161.x)

6 Parfitt AM. The hyperparathyroidism of chronic renal failure: a disorder of growth. Kidney International $1997 \quad 52$ 3-9. (doi:10.1038/ki.1997.297)

7 Parfitt AM, Wang Q \& Palnitkar S. Rates of cell proliferation in adenomatous, suppressed, and normal parathyroid tissue: implications for pathogenesis. Journal of Clinical Endocrinology and Metabolism $1998 \mathbf{8 3}$ 863-869. (doi:10.1210/jc.83.3.863)

8 Yano S, Sugimoto T, Tsukamoto T, Chihara K, Kobayashi A, Kitazawa S, Maeda S \& Kitazawa R. Decrease in vitamin D receptor and calcium-sensing receptor in highly proliferative parathyroid adenomas. European Journal of Endocrinology 2003148 403-411.

9 Gogusev J, Duchambon P, Hory B, Giovannini M, Goureau Y, Sarfati E \& Drüeke TB. Depressed expression of calcium receptor in parathyroid gland tissue of patients with hyperparathyroidism. Kidney International $1997 \quad \mathbf{5 1} \quad 328-336$. (doi:10.1038/ki.1997.41)

10 Tokumoto M, Tsuruya K, Fukuda K, Kanay H, Kuroki S \& Hirakata H. Reduced p21, p27 and vitamin D in the nodular hyperplasia in patients with advanced secondary hyperparathyroidism. Kidney International 200662 1196-1207. (doi:10.1111/ j.1523-1755.2002.kid585.x)

11 Wang Q, Palnitkar S \& Parfitt AM. The basal rate of cell proliferation in normal human parathyroid tissue. Implications for the pathogenesis of hyperparathyroidism. Clinical Endocrinology 199746 343-349. (doi:10.1046/j.1365-2265.1REF15=10. 1111/j.1744-9987.2006.00364.x)

12 Wang W, Johansson H, Kvasnicka T, Farnebo LO \& Grimelius L. Detection of apoptotic cells and expression of Ki-67 antigen, bcl-2, p53 oncoproteins in human parathyroid adenoma. APMIS: Acta Pathologica, Microbiologica, et Immunologica Scandinavica 1996104 789-796. (doi:10.1111/j.1699-0463.1996.tb04944.x)

13 Wada Y, Kunimura T, Sato S, Hisayuki T, Sato M, Imataka H, Yamashita N, Akizawa T \& Moroboshi T. Proliferating potential and apoptosis in the development of secondary hyperparathyroidism: a study based on Ki-67 immunohistochemical staining and 
the terminal dUTP nick-end labeling assay. Therapeutic Apheresis and Dialysis 200812 319-328. (doi:10.1111/j.1744-9987. 2008.00594.x)

14 Indridason OS, Heath H III, Khosla S, Yohay DA \& Quarles LD. Non-suppressible parathyroid hormone secretion is related to gland size in uremic secondary hyperparathyroidism. Kidney International 199650 1663-1671. (doi:10.1038/ki.1996.483)

15 Tominaga Y, Inaguma D, Matsuoka S, Tahara H, Kukita K, Kurihara S, Onoda N, Tsuruta Y, Tsutsui S, Ohta K et al. Is the volume of the parathyroid gland a predictor of maxacalcitol response in advanced secondary hyperparathyroidism? Therapeutic Apheresis and Dialysis 200610 761-771. (doi:10.1111/j.17449987.2006.00364.x)

16 Tominaga Y, Matsuoka S \& Uno N. Surgical and medical treatment of secondary hyperparathyroidism in patients on continuous dialysis. World Journal of Surgery $2009 \quad 33 \quad 2335-2342$. (doi:10.1007/s00268-009-9943-3)

17 Riccardi D \& Martin D. The role of the calcium-sensing receptor in the pathophysiology of secondary hyperparathyroidism. NDT Plus 20081 i7-i11. (doi:10.1093/ndtplus/sfm038)

18 Wada M, Furuya Y, Sakiyama J, Kobayashi N, Miyata S, Ishii H \& Nagano N. The calcimimetic compound NPS R-568 suppresses parathyroid cell proliferation in rats with renal insufficiency: control of parathyroid cell growth via a calcium receptor. Journal of Clinical Investigation $1997 \quad \mathbf{1 0 0} \quad 2977-2983$. (doi:10.1172/ JCI119851)

19 Mizobuchi M, Ogata H, Hatamura I, Saji F, Koiwa F, Kinugasa E, Koshikawa $S$ \& Akizawa T. Activation of calcium sensing receptor accelerates apoptosis in hyperplastic parathyroid cells. Biochemical and Biophysical Research Communications 2007362 11-16. (doi:10.1016/j.bbrc.2007.07.177)

20 Chin J, Miller SC, Wada M, Nagano N, Nemeth EF \& Fox J. Activation of the calcium receptor by a calcimimetic compound halts the progression of secondary hyperparathyroidism in uremic rats. Journal of the American Society of Nephrology 200011 903-911.

21 Colloton M, Shatzen E, Miller G, Stehman-Breen C, Wada M, Lacey D \& Martin D. Cinacalcet $\mathrm{HCl}$ attenuates parathyroid hyperplasia in a rat model of secondary hyperparathyroidism. Kidney International 200567 467-476. (doi:10.1111/j.15231755.2005.67103.x)

22 Rodriguez ME, Almaden Y, Cañadillas S, Canalejo A, Siendones E, Lopez I, Aguilera-Tejero E, Martin D \& Rodriguez M. The calcimimetic R-568 increases vitamin D receptor expression in rat parathyroid glands. American Journal of Physiology. Renal Physiology 2007292 F1390-F1395. (doi:10.1152/ajprenal. 00262.2006)

23 Miller G, Davis J, Shatzen E, Colloton M, Martin D \& Henley CM. Cinacalcet $\mathrm{HCl}$ prevents development of parathyroid gland hyperplasia and reverses established parathyroid gland hyperplasia in a rodent model of CKD. Nephrology, Dialysis, Transplantation 201227 2198-2205. (doi:10.1093/ndt/gfr589)

24 Tanaka M, Tominaga Y, Sawatari E, Itoh K, Matsushita K, Matsushita K, Matsuoka S, Ueki T, Goto N, Sato T et al. Infarction of mediastinal parathyroid gland causing spontaneous remission of secondary hyperparathyroidism. American Journal of Kidney Diseases 200444 762-767. (doi:10.1053/j.ajkd.2004.06.023)

25 Komaba H, Takeda H, Abe T, Komaba K, Otsuki N, Nibu K, Umezu M \& Fukagawa M. Spontaneous remission of severe hyperparathyroidism with normalization of the reversed whole PTH/intact PTH ratio in a hemodialysis patient. Nephrology, Dialysis, Transplantation 200823 1760-1762. (doi:10.1093/ndt/ gfm891)

26 Taniguchi M, Tokumoto M, Matsuo D, Motoyama K, Sugitani A, Kuroki S, Yotsueda H, Tsuruya K, Hirakata H \& Iida M. Persistent hyperparathyroidism in renal allograft recipients: vitamin D receptor, calcium sensing receptor, and apoptosis. Kidney International 200670 363-370. (doi:10.1038/sj.ki.5001549)

27 Bravo J, Esteban RJ, Medina A, Palacios ME, Pérez A, Perán F, de Dios Luna J, González J, Prados MD \& Asensio C. Successful kidney transplantation reduces hyperplastic parathyroid gland. Transplantation Proceedings 200739 125-131. (doi:10.1016/j. transproceed.2006.10.208)

28 Ichii M, Ishimura E, Okuno S, Chou H, Kato Y, Tsuboniwa N, Nagasue K, Maekawa K, Yamakawa T, Inaba M et al. Decreases in parathyroid gland volume after cinacalcet treatment in hemodialysis patients with secondary hyperparathyroidism. Nephron. Clinical Practice 2010115 c195-c202. (doi:10.1159/000313035)

29 Meola M, Petrucci I \& Barsotti G. Long-term treatment with cinacalcet and conventional therapy reduces parathyroid hyperplasia in severe secondary hyperparathyroidism. Nephrology. Dialysis, Transplantation 2009 24 982-989. (doi:10.1093/ndt/gfn654)

30 Komaba H, Nakanishi S, Fujimori A, Tanaka M, Shin J, Shibuya K, Nishioka M, Hasegawa H, Kurosawa T \& Fukagawa M. Cinacalcet effectively reduces parathyroid hormone secretion and gland volume regardless of pretreatment gland size in patients with secondary hyperparathyroidism. Clinical Journal of the American Society of Nephrology 20105 2305-2314. (doi:10.2215/CJN. 02110310)

31 Vulpio C, Bossola M, De Gaetano A, Maresca G, Di Stasio E, Zagaria L, Luciani G, Giordano A \& Castagneto M. Parathyroid gland ultrasound patterns and biochemical findings after one-year cinacalcet treatment for advanced secondary hyperparathyroidism. Therapeutic Apheresis and Dialysis $2010 \quad 14$ 178-185. (doi:10.1111/j.1744-9987.2009.00781.x)

32 Kakuta T, Tanaka R, Kanai G, Sawaya A, Hirukawa T, Sato A \& Saito A. Can cinacalcet replace parathyroid Intervention in severe secondary hyperparathyroidism? Therapeutic Apheresis and Dialysis 200913 S20-S27. (doi:10.1111/j.1744-9987.2009.00772.x)

33 Lomonte C, Vernaglione L, Chimienti D, Bruno A, Cocola S, Teutonico A, Cazzato F \& Basile C. Does vitamin D receptor and calcium receptor activation therapy play a role in the histopathologic alterations of parathyroid glands in refractory uremic hyperparathyroidism? Clinical Journal of the American Society of Nephrology 20083 794-799. (doi:10.2215/CJN.04150907)

34 Sumida K, Nakamura M, Ubara Y, Marui Y, Tanaka K, Takaichi K, Tomikawa S, Inoshita N \& Ohashi K. Histopathological alterations of the parathyroid glands in haemodialysis patients with secondary hyperparathyroidism refractory to cinacalcet hydrochloride. Journal of Clinical Pathology 201164 756-760. (doi:10.1136/jclinpath-2011-200100)

35 Martins P, Schmitt F, Almeida H \& Frazao JM. Evaluation of parathyroid gland angiogenesis in chronic kidney disease associated with secondary hyperparathyroidism. Nephrology, Dialysis, Transplantation 200823 2889-2894. (doi:10.1093/ $\mathrm{ndt} / \mathrm{gfn} 150)$

36 Ritter CS, Haughey BH, Miller B \& Brown AJ. Differential gene expression by oxyphil and chief cells of human parathyroid glands. Journal of Clinical Endocrinology and Metabolism 201297 E1499-E1505. (doi:10.1210/jc.2011-3366)

37 Valimaki S, Farnebo F, Forsberg L, Larsson C \& Farnebo LO. Heterogeneous expression of receptor mRNAs in parathyroid glands of secondary hyperparathyroidism. Kidney International 200160 1666-1675. (doi:10.1046/j.1523-1755.2001.00986.x)

38 Christie AC. The parathyroid oxyphil cells. Journal of Clinical Pathology 196720 591-602. (doi:10.1136/jcp.20.4.591)

39 Ritter CS, Haughey BH, Armbrecht HJ \& Brown AJ. Distribution and regulation of the 25-hydroxyvitaminD $D_{3} 1 \alpha$-hydroxylase in human parathyroid glands. Journal of Steroid Biochemistry and Molecular Biology 2012130 73-80. (doi:10.1016/j.jsbmb.2012. 01.010)

40 McGregor DH, Lotuaco LG, Rao MS \& Chu HL. Functioning oxyphil adenoma of parathyroid gland an ultrastructural and biochemical study. American Journal of Pathology 197892 691-712.

41 Szende B, Farid P, Végsô G, Perner F \& Kopper L. Apoptosis and P53, Bcl-2 and Bax gene expression in parathyroid glands of patients with hyperparathyroidism. Pathology Oncology Research 200410 98-103. (doi:10.1007/BF02893463) 
42 Garcia de la Torre N, Buley I, Wass JAH, Jackson DG \& Turner HE. Angiogenesis and lymphangiogenesis in parathyroid proliferative lesions. Journal of Clinical Endocrinology and Metabolism 200489 2890-2896. (doi:10.1210/jc.2003-031651)

43 Lazaris AC, Tseleni-Balafouta S, Papathomas T, Brousalis T, Thomopoulou G, Agrogiannis G \& Patsouris ES. Immunohistochemical investigation of angiogenic factors in parathyroid proliferative lesions. European Journal of Endocrinology 2006154 827-833. (doi:10.1530/eje.1.02168)

44 Katoh R. Angiogenesis in endocrine glands: special reference to the expression of vascular endothelial growth factor. Microscopic Research and Technique 200360 181-185. (doi:10.1002/jemt. 10256)

45 Turner HE, Harris AL, Melmed S \& Wass JAH. Angiogenesis in endocrine tumors. Endocrine Reviews $2003 \quad 24$ 600-632. (doi:10.1210/er.2002-0008)
46 Imanishi Y, Kawata T, Kenko T, Wada M, Nagano N, Miki T, Arnold A \& Inaba M. Cinacalcet $\mathrm{HCl}$ suppresses cyclin D1 oncogene-derived parathyroid cell proliferation in a murine model for primary hyperparathyroidism. Calcified Tissue International 201189 29-35. (doi:10.1007/s00223-011-9490-4)

47 Vulpio C, Bossola M, Magalini SC, Silvestri P, Fadda G, Ciliberti M, D'Andrea ML \& Maresca G. Parathyroid-gland ultrasonography in clinical and therapeutic evaluation of renal secondary hyperparathyroidism. La Radiologia Medica, 2013 (In press). (doi:10.1007/ s11547-012-0882-x)

Received 29 October 2012

Revised version received 1 March 2013

Accepted 21 March 2013 